\title{
PENERAPAN APLIKASI E-COMMERCE PADA CLOTHING KICKOUT APPAREL
}

\author{
Firdian Andriyanto ${ }^{1)}$, Lusi Fajarita ${ }^{2)}$ \\ ${ }^{1}$ Sistem Informasi, Fakultas Teknologi Informasi, Universitas Budi Luhur \\ ${ }^{1,2}$ Jl. Raya Ciledug, Petukangan Utara, Kebayoran Lama, Jakarta Selatan 12260 \\ E-mail : firdian1996@gmail.com ${ }^{1)}$, lusi.fajarita@budiluhur.ac.id ${ }^{2)}$
}

\begin{abstract}
Abstrak
E-Commerce (Elektronic Commerce) atau bisa dinamakan pemasaran barang dan jasa melalui internet. Clothing Kickout Apparel merupakan sebuah usaha di Indonesia, awalnya barang yang diproduksi berupa kaos, tetapi seiring perkembangan kebutuhan permintaan pelanggan dan berkembangnya cara berpakaian (style), produknya pun meluas hingga ke jaket, topi, tote bag dan aksesoris lainnya. Adapun masalah yang dihadapi adalah stok lama pada Clothing Kickout Sering tidak terjual, informasi mengenai promo yang tidak teralisasi kepada pada pelanggan Clothing Kickout Apparel, kesulitan untuk mencari produk yang ingin dipesan, dengan adanya permasalahan diatas maka diperlukan E-Commerce pada Clothiing Kickout Apparel guna membantu untuk mempermudah pemasaran produk barang yang dijual, pada proses implementasi e-commerce ini yang digunakan adalah bahasa pemrograman PHP database digunakan untuk penyimpanan data hasil yang diperoleh adalah penerapan aplikasi e-commerce pada clothing kickout apparel yang bertujuan untuk mempermudah proses pemasaran dan penjualan barang.
\end{abstract}

Kata kunci: E-Commerce, Clothing, Pemasaran Produk.

\section{PENDAHULUAN}

E-Commerce atau bisa disebut dengan website penjualan dan pemasaran barang melalui jaringan komputer.

Clothing sebutan yang digunakan untuk memproduksi pakaian untuk menciptakan nama produk sendiri. Clothing Kickout Apparel merupakan sebuah usaha di Indonesia, awalnya barang yang diproduksi berupa kaos, tetapi seiring perkembangan kebutuhan permintaan pelanggan dan berkembangnya cara berpakaian (style), produknya pun meluas hingga ke topi, celana, tas dan aksesoris lainnya. Umumnya usaha dengan konsep Clothing mengutamakan kebutuhan untuk anak-anak muda dan mahasiswa. Semakin berkembangnya serta semakin banyak kebutuhan penampilan dan layanan kebutuhan fashion, maka Clothing Kickout Apparel berinisiatif untuk membuka suatu usaha clothing yang dimana produknya berdasarkan update-update fashion masa kini dan juga akan menyediakan layanan pemesanan untuk para konsumen (order) sehingga konsumen bisa menikmati hasil pesanannya sesuai keinginan dan kebutuhan.

Rancangan e-commerce untuk Clothing Kickout Apparel adalah sebagai pengembangan sistem penjualan pada Clothing Kickout Apparel, karena penjualan Clothing Kickout Apparel saat ini menurun, dengan dirancangnya sebuah e-commerce, untuk Clothing Kickout Apparel ini, penjualan pada Clothing Kickout Apparel dapat meningkat.

Kebutuhan akan informasi produk sulit untuk dicari, membuat proses pelayanan Clothing tersebut menjadi lambat.
Tidak adanya pencatatan untuk konfirmasi pembayaran sehingga mengakibatkan bagian penjualan dan pemilik sulit mengetahui pelanggan mana yang sudah melakukan pembayaran

Kurang Optimalnya dalam melakukan pemesanan karena pelanggan hanya dapat melakukan pemesanan ke warehouse dan media sosial.

Kesulitan dalam mencari produk yang ingin dipesan

Proses pelayanan Clothing menjadi lambat karena belum memiliki sistem e-commerce

Informasi promo pada Clothing Kickout Apparel tidak tersampaikan dengan baik terhadap pelanggan

Mempermudah untuk mengetahui ketersedian stok barang yang masih tersedia dan dapat mencari produk yang tersedia yang dibutuhkan pelanggan.

Mempermudah dalam penyajian informasi kepada pelanggan dengan tepat dan akurat

Dengan adanya e-commerce ini, Clothing Kickout Appparel dapat mengetahui stok yang tersedia dan yang sudah laku terjual.

Stok lama yang dimiliki oleh Clothing Kickout Apparel tidak terjual, sehingga pihak Clothing tersendiri mengalami kesulitan untuk memasarkan stok lama.

Sistem adalah sekelompok tujuan yang berkaitan untuk mencapai tujuan bersama.[1]

Konsep dasar analisa sistem merupakan suatu penyelesaian terhadap masalah dan memecahkan masalah untuk diterapkan ke sistem.[2] 
Business Model Canvas adalah suatu struktur yang membahas model Bisnis agar dapat dipahami.. [3]

Kebutuhan akan informasi produk sulit untuk dicari, membuat proses pelayanan Clothing tersebut menjadi lambat.

Tidak adanya pencatatan untuk konfirmasi pembayaran sehingga mengakibatkan bagian penjualan dan pemilik sulit mengetahui pelanggan mana yang sudah melakukan pembayaran

Kurang Optimalnya dalam melakukan pemesanan karena pelanggan hanya dapat melakukan pemesanan ke warehouse dan media sosial.

Kesulitan dalam mencari produk yang ingin dipesan

Proses pelayanan Clothing menjadi lambat karena belum memiliki sistem e-commerce

Informasi promo pada Clothing Kickout Apparel tidak tersampaikan dengan baik terhadap pelanggan

Penelitian oleh [4] yaitu Sistem Penjualan Berbasis Web (E-Commerce) Pada Tata Distro Kabupaten Pacitan. penelitian ini menciptakan tujuan pemasaran penjualan yang lebih efektif daripada sebelumnya pada Tata Distro kelurahan Ploso kabupaten Pacitan sehingga mendapatkan omset tinggi pada hasil penjualan Tata Distro. Jurnal Bianglala Informatika Vol 3 No 2 September 2015. Hasil dan kesimpulan dari penelitian ini adalah Dengan diterapkannya pemasaran pada Tata Distro, maka pihak toko dapat terbantu kegiatan pemasaran pada produk fashion secara online.

Penelitian oleh [5] yaitu Penerapan ECommerce Pada Gudang Distro Palembang. Tujuan dari penelitian ini yaitu mempermudah pembeli didalam melakukan proses pembelian. Jurnal Vol 5, No 1 (2016). Hasil dan Kesimpulan Penggunaan sistem ini mudah digunakan oleh pelanggan.

\section{METODE PENELITIAN}

\subsection{Kerangka Kerja Penelitian}

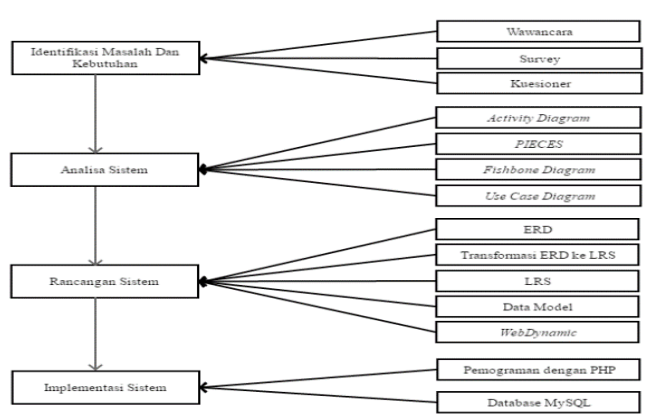

Gambar 1. Kerangka Kerja Penelitian
Pada hasil penelitian ini, disajikan Kerangka kerja penelitian yang terlihat pada gambar 1.

Adapun pembahasan tiap masing tahap kerangka kerja penelitan ialah sebagai berikut:

1. Identifikasi Masalah dan Kebutuhan

Identifikasi kebutuhan dilakukan tahapan yaitu wawancara, survey, kuesioner

2. Analisa Sistem

Proses analisa sistem dilakukan berbagai tahap yaitu pembuatan activity diagram, pieces, fishbone diagram, usecase diagram

3. Perancangan Sistem

Perancangan sistem dilakukan

berbagai tahap yaitu pembuatan ERD, transformasi ERD, LRS, Data Model, Web Dynamic

4. Implementasi Sistem

Tahapan ini implementasi sistem dilakukan yaitu pemrograman dengan PHP, Database MySql

\subsection{Business Model Canvas}

Business Model Canvas merupakan suatu model Bisnis dengan disajikan dalam bentuk gambar agar dapat dimengerti.

\section{HASIL DAN PEMBAHASAN}

\subsection{Bussiness Model Canvas}

Business Model Canvas adalah suatu model Bisnis dengan disajikan dalam bentuk gambar agar dapat dimengerti. Bussines model canvas dapat dilihat pada gambar 2 sebagai berikut.

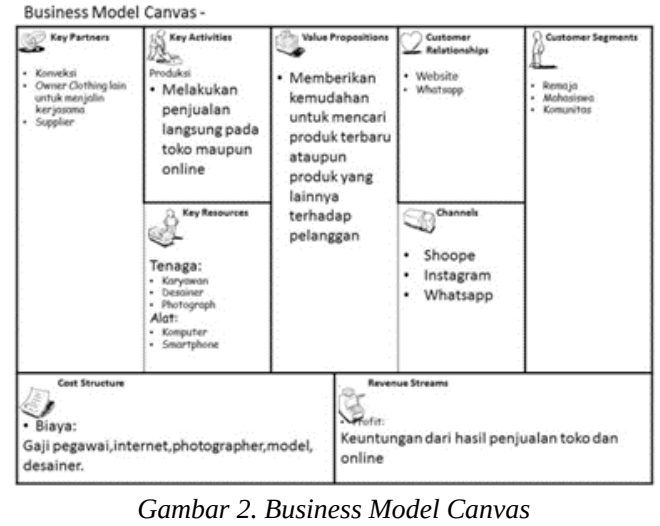

\subsection{Perancangan Sistem}

a. Use Case Diagram

Berikut ini adalah usecase diagram admin yang dapat dilihat pada gambar 3 sebagai berikut 


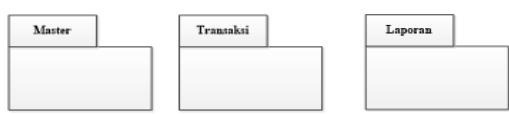

Gambar 3. Use Case Diagram Untuk Admin

b. Use Case Diagram Master untuk Admin

Berikut ini adalah usecase diagram master admin yang dapat dilihat pada gambar 4 sebagai berikut.

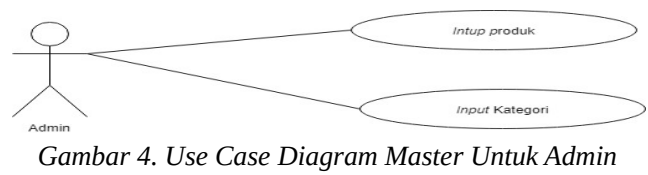

c. Use Case Diagram Transaksi untuk Admin

Berikut ini adalah usecase diagram transaksi admin yang dapat dilihat pada gambar 5 adalah sebagai berikut.

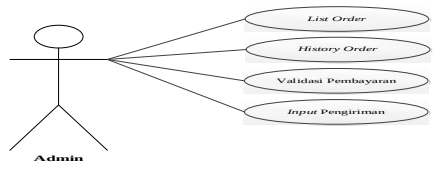

d. Use Case Diagram Master untuk Pelanggan

Berikut ini adalah usecase diagram master pelanggan yang dapat dilihat pada gambar 6 sebagai berikut.

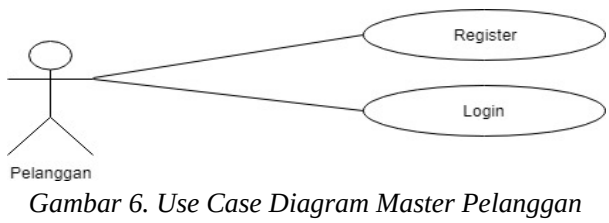

\subsection{Model Data}

Pada model data class diagram dapat dilihat pada gambar 7 sebagai berikut.

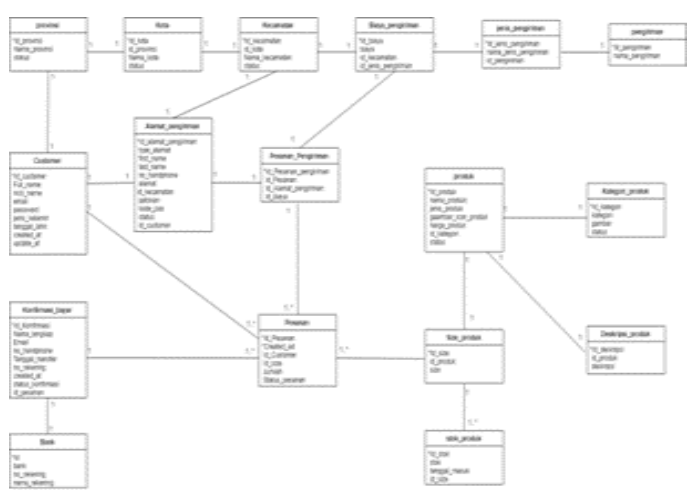

Gambar 7. Model Data Class Diagram

\subsection{Rancangan Layar}

a. Rancangan Layar Admin

Gambar 8 adalah gambar rancangan layar admin yang dapat dilihat pada gambar 8 berikut ini

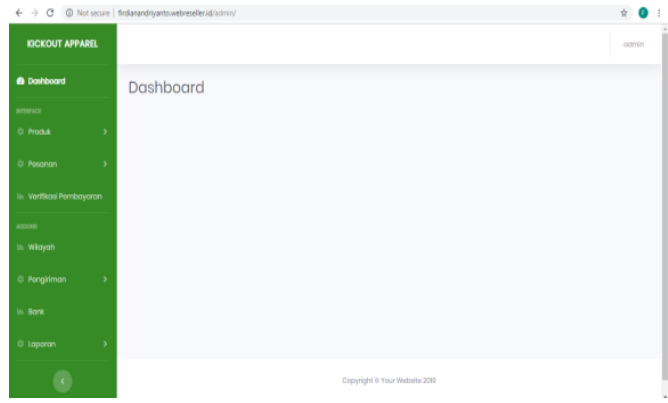

Gambar 8. rancangan layar home admin

b. Rancangan layar produk admin

Pada gambar berikut ini adalah rancangan layar produk admin yang dapat dilihat pada gambar 9 sebagai berikut

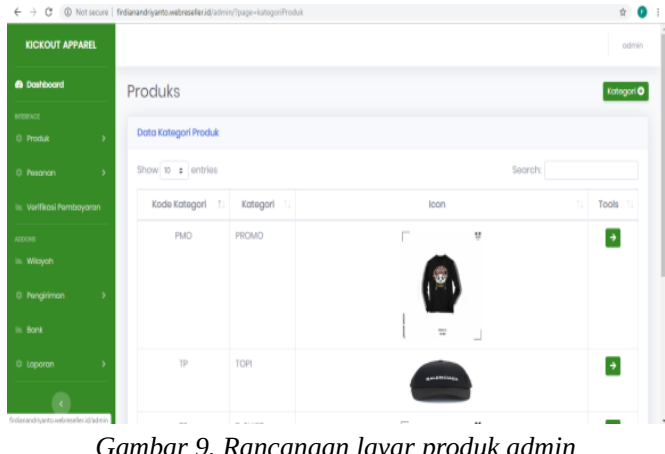

c. Rancangan layar home pelangan

Pada gambar berikut ini adalah rancangan layar home pelanggan yang dapat dilihat pada gambar 10 sebagai berikut.

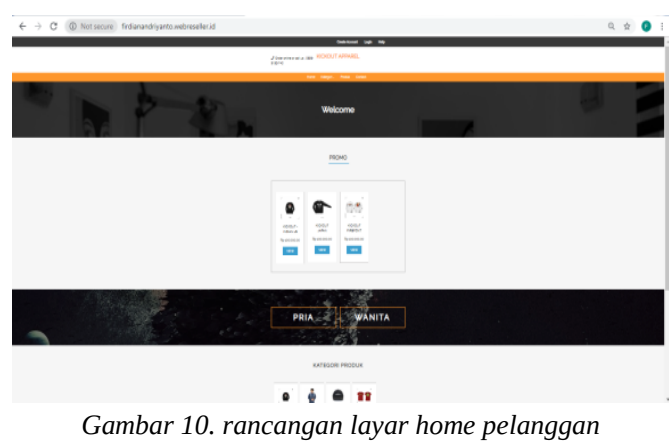

d. Rancangan layar stock barang

Pada gambar berikut ini adalah rancangan layar stock barang yang dapat dilihat pada gambar 11 sebagai berikut. 


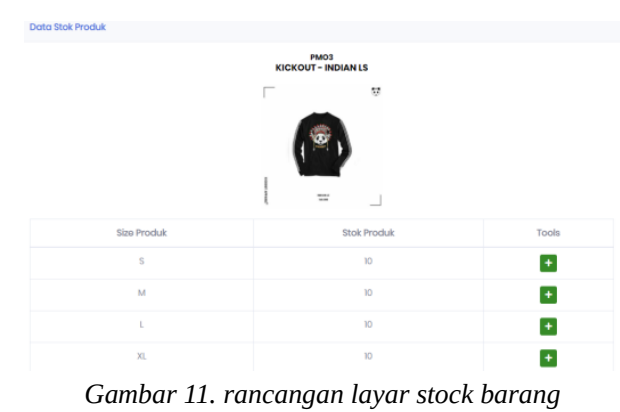

e. Rancangan layar produk yang dijual

Pada gambar berikut ini adalah rancangan layar produk yang dijual dapat dilihat pada gambar 12 sebagai berikut.

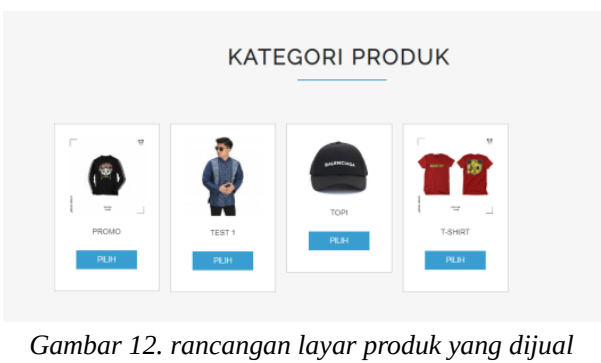

f. Rancangan layar promosi produk

Pada gambar berikut ini adalah rancangan layar promosi produk yang dapat dilihat pada gambar 13 sebagai berikut.

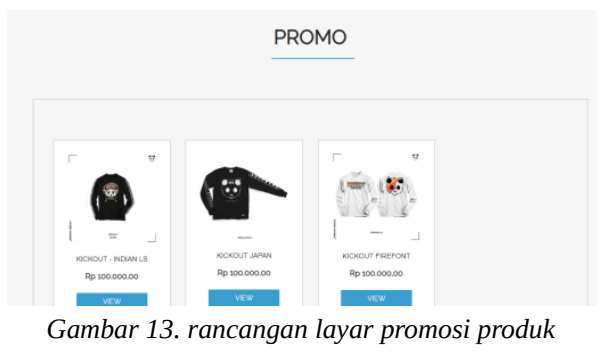

\section{KESIMPULAN}

1. Admin yang bekerja pada Clothing Kickout Apparel menghadapi kesulitan dalam mencari informasi tentang produk yang akan di pesan oleh pelanggan, dengan rancangan sistem e-commerce ini, admin, pelanggan dan owner dapat mencari produk dengan mudah.

2. Penjualan pakaian pada Clothing Kickout Apparel mempunyai promosi produk tertentu, untuk merealisasikan informasi produk promo ini belum optimal, dengan rancangan e-commerce ini, informasi produk lama yang memiliki promosi dapat di realisasikan atau ditampilkan secara online.
3. Membuat Sistem Konfirmasi Pembayaran agar admin dan owner dapat mengetahui pelanggan mana yang sudah melakukan pemesan dan pembayaran.

4. Mempermudah pelanggan dalam melakukan pemesanan tanpa harus datang langsung ke warehouse atau menghubungi media sosial dan mengetahui pelanggan yang sudah bertransaksi.

5. Membuat sistem dalam membuat laporan produk terjual secara online sehingga admin dapat mengetahui produk yang sudah terjual setiap hari, bulan dan tahunnya.

6. Membuat Sistem dalam laporan produk terlaris secara online sehingga admin dan owner dapat mengetahui produk terlaris agar mempermudah membuat produk yang paling sering dibeli oleh pelanggan.

\section{DAFTAR PUSTAKA}

[1] Iswandy, E. Sistem Penunjang Keputusan Untuk Menentukan Penerimaan Dana Santunan Sosial Anak Nagari Dan Penyalurannya Bagi Mahasiswa dan Pelajar Kurang Mampu di Kenagarian Barung Barung Belantai Timur. Teknoif, 3(2), 2015, pp. 70 79.

[2] Welim, Y. Y., \& Sakti, A. R. Rancang Bangun Sistem Informasi Administrasi Pengelolaan Dana Masjid Pada Yayasan Al-Muhajiriin, Tangerang. Simetris : Jurnal Teknik Mesin, Elektro Dan Ilmu Komputer, 7(1), 2017, p. 29.

[3] Sylvia Saragi Sitio, V. Journal of Economics and Business Aseanomics ( JEBA) KARAKTERISTIK PENUMPANG PENGGUNA KRL COMMUTER. Karakteristik Penumpang KRL Computer Line Jabodetabek, 2(1). 2017.

[4] Ahmia, M. and Belbachir, H. 'p, q-Analogue of a linear transformation preserving log-convexity', Indian Journal of Pure and Applied Mathematics, 49(3), 2018, pp. 549-557.

[5] Marcallina, D. and Wahyuningsih, D. 'Penerapan Ecommerce dengan Metode Costumer Relationship Management (CRM) Berbasis Website (Studi Kasus: Gudang Distro Palembang)', Jurnal Sisfokom (Sistem Informasi dan Komputer), 5(1), 2016, p. 40. 